RPA Journals

\section{IJEKM}

International Journal of Education and Knowledge Management (IJEKM) Journal Homepage: https://rpajournals.com/ijekm

\title{
Investigating the Relationship between English Language Anxiety and the Achievement in IELTS Speaking Module among Students Attending IELTS Preparatory Classes
}

\author{
Nadia Hanif ${ }^{*}$ \\ Maria Sajid ${ }^{2}$ \\ University of Management and Technology, Lahore, Pakistan' \\ Bahria University, Lahore Campus, Pakistan ${ }^{2}$
}

\begin{abstract}
The purpose of this study is to investigate the impact of English language anxiety upon students' scores in IELTS speaking module attending IELTS preparatory classes in three mainstream English language institutes of Lahore. In this research, the correlation between English language anxiety and candidates' age, gender, years of education and medium of instruction is found out. An inventory Foreign Language Classroom Anxiety Scale (FLCAS) designed by Horwitz, Horwitz and Cope (1986) is adapted for the current study. 33 items of the survey are based on i) communication apprehension, ii) fear of negative evaluation and iii) test anxiety. The survey is administered to 60 students of three different IELTS preparatory institutes of Lahore. Obtained data is analysed using SPSS version 20. Independent t-test, ANOVA and Pearson coefficient is applied to check the correlation. Results show that there is a strong negative correlation between females' FLA and their IELTS speaking scores. Candidates who have Urdu as a medium of instruction face a higher level of FLA and candidates having 12-14 years of education experience the highest level of anxiety among the various age groups. Younger IELTS aspirants experience highest level of FLA as compared to the older age groups.
\end{abstract}

Keywords: IELTS, Language Anxiety, FLA, Speaking, Second Language.

*Corresponding author: Nadia Hanif; Email: nadiahanif@hotmail.com DOI: https://doi.org/10.37227/IJEKM-2020-02-41

\section{Introduction}

Importance of English language in Pakistan has been considered widely and emphasized to make it a compulsory subject (Sarwar, 2002) and English Language has become a significant factor for individuals to achieve their goals and excel in their lives (Sharma, 2004). Students do not have much exposure and interaction with the English language in their everyday life (Bashiruddin, 2003). Despite knowing English language, there is a certain fear to use it in public (Esmail, Ahmed \& Noreen, 2015). After learning English Language for eleven years, students are still unable to speak it properly when they reach university (Jalaluddin, 2006). English Language is often used as 'Foreign Language' - a term for a language (other than the native language) which is used outside the setting where it is originally or usually spoken; a language that might be used in the classroom but not in the society being taught (Moeller and Catalano, 2015). 
Learning a language other than an individual's native language involves certain uneasy feelings such as sweating, fidgeting, shivering and fumbling; Horwitz, Horwitz and Cope (1986) for the first time proposed that anxiety involved in language learning was a specific anxiety element which they named as Foreign Language Anxiety (FLA). Horwitz, Horwitz and Cope (1986) argued that foreign language anxiety is a specific condition that is likely to be related to three kinds of anxieties, i.e. Communication Apprehension (CA), Fear of Negative Evaluation (FNE) and Test Anxiety (TA). They presented an inventory called Foreign Language Classroom Anxiety (FLCA) to measure second language learning anxiety among learners. The items included in FLCA were based on the above mentioned three categories of anxiety, where the results related to anxiety and language learning/achievement have been fairly constant, depicting an average uniform connection with achievement and anxiety (Horwitz et al., 1986). CA denotes an individual's uneasiness while talking to others Horwitz, Horwitz and Cope (1986). FNE is a constituent of an individual's preconception and more than required concern with academic and professional estimation of their performance and proficiency in the foreign language (MacIntyre and Gardener, 1991). It is humanly not possible to acquire a language without making errors (James, 2013).

However for some individuals, errors can be a source of anxiety because they perceive that there would be numerable difficulties in creating a positive social impact when using a foreign language (MacIntyre and Gardener 1991.Test anxiety is also a form of fear of evaluation, in formal situations. People experiencing test anxiety usually complain of sweating, dry throat, forgetting the learnt content, trembling and fidgeting before or during the test-taking. Their anxiety in foreign language contexts usually gets triggered resulting in their poor performance (MacIntyre and Gardner 1991). It is suggested that an individual's poor performance in foreign language learning is a cause of anxiety and not a result of it (Sparks \& Granshcow, 1993). In her further research on language anxiety and achievement Horwitz (1990) discusses various possible sources of this anxiety such as difficulty faced by individuals in genuine self-presentation and different language teaching practices. Elaine (2002) studied the effect of students' level of anxiety on their performance on an oral test of French and examined the attitudes of highly anxious learners towards that exam, where the researcher argues that among various variables affecting language learning, foreign language anxiety is a potential one and that culture, attitude and tradition are attached to language learning at large.

Dewaele (2007) studied Communicative Anxiety/Foreign Language Anxiety of multilingual individuals speaking in public, portrayed that multi-lingual face CA in L1 during stressful situations and higher level of FLA in language acquired in later years of life. Female participants only faced higher degrees of language anxiety during speaking L1 in public. However, older subjects were likely to report higher levels of communication anxiety throughout L1, L2, L3 and L4 (Dewaele, 2007). An account of research (Noreen, Ahmed and Ismail, 2015) on students' attitudes, motivation and language anxiety of grade 12 of a distinguished college of Faisalabad projected that females have a higher degree of motivation and positive attitude towards English language learning, while males have a higher degree of anxiety towards second language. Renowned journalist Mustafa (2012) says that to this date there has been no well-defined medium of instruction in Pakistan and there are two extremes - wealthy elite purely English medium schools and middle and lower class mixed-medium schools, the latter creating an utter linguistic chaos for students who aspire to study abroad and have to sit IELTS test.

International Journal of Education and Knowledge Management (IJEKM) 
Taking IELTS test is known to be a challenging task for Pakistanis (Memon, 2015). And all the aspirants may not necessarily have a good background of English language learning (Memon, 2015). This study is aimed at finding out the impact of English Language Anxiety on students' IELTS speaking scores; determine the correlation of English Language Anxiety (ELA) measured through FLCAS and its sub-scales: CA, FNE and TA with students' original IELTS speaking scores. It also intends to explore the relationship between FLCAS and its sub-scales and IELTS speaking scores in terms of age, gender, and years of education and medium of instruction.

The research question is as follows:

- What is the relationship of FLCAS and its sub-scales with the achievement in IELTS Speaking Module of students attending IELTS Preparatory Classes?

- Sub-Questions of this study in relation to their IELTS speaking score are as follows:

- What is the correlation of students' IELTS speaking scores and obtained level of anxiety (FLCAS and its sub-scales)?

- What is the impact of age upon FLCAS and its sub-scales?

- What is the impact of gender upon FLCAS and its sub-scales?

- What is the impact of medium of instruction upon FLCAS and its subscales?

- What is the impact of years of education upon FLCAS and its sub-scales?

\section{Literature Review}

The definition of anxiety varies from a mixture of evident behavioural features which can be scientifically studied to introspections that are epistemologically unapproachable (Casado \& Dereshiwsky, 2001).

\section{Definition of Anxiety}

Freud defined anxiety as "something felt," an emotional state experienced by an individual, and which contains several other feelings, such as tension, worry, apprehension and nervousness supplemented by physiological arousal (Pekker, 2012). Pekker (2012) says that in coherence with Darwin's theory of evolution, Freud observed that anxiety assisted motivational behaviour among individuals if exposed to threatening conditions.

\section{Academic Anxiety}

Zhang (2001) defined anxiety as "the psychological tension that the learner goes through in performing a learning task". Cassady (2010) introduced a term "academic anxiety" as "a unifying formulation for the collection of anxieties learners experience while in schools". Foreign language anxiety (FLA) as proposed by many researchers (Casado \& Dereshiwsky, 2001; Coryell \& Clark, 2009; Kostić-Bobanović, 2009; Liu, 2006; Liu \& Jackson, 2008; MacIntyre \& Gardner, 1994a; Tallon, 2009; Von Wörde, 2003 as cited in Trang, 2011) that foreign language anxiety is not an ambiguous variable, examined and measured under particular situations where anxiety provoking conditions are induced upon the individual, rather it is a disturbing reality for a lot of students. 


\section{Foreign Language Anxiety}

Several researchers have provided different definitions for foreign language anxiety. Clement (1980) defined foreign language anxiety as a complex construct that deals with learners' psychology in terms of their feelings, self-esteem, and self-confidence. Young (1992) emphasized upon the unique characteristic of FLA and defined it as a complex psychological phenomenon unusual to language learning. MacIntyre and Gardner (1994) defined FLA as the feeling of tension and apprehension specifically associated with second or foreign language exposure, or the worry and negative emotional reaction arousal when learning or using a second or foreign language (MacIntyre, 1999). All of these definitions are constructed around the claim made by Horwitz, Horwitz and Cope (1986) that FLA is "a phenomenon related to, but distinguishable from other specific anxieties". Hilgard, Atkinson \& Atkinson, (1971) define language anxiety as a psychological construct, commonly described by the psychologists as a state of apprehension, a vague fear that is only indirectly associated with an object. Many people find foreign language learning stressful in classroom situations specifically, and many researchers have found specific anxiety reactions connected with various school tasks, for example, tests and academics (Horwitz et al., 1986).

\section{Components of Foreign Language Anxiety}

Brown (2000) suggested that there are three components of foreign language anxiety, i.e. Communication apprehension: This type of anxiety is produced from the individual's incapability to effectively express established ideas and thoughts, fear of negative social evaluation, created from an individual's requirement to make an impressive social image and test anxiety or apprehension over academic evaluation.

These three components of foreign language anxiety are the categories provided by Horwitz, Horwitx and Cope (1986) in their famous survey FLCAS. McCroskey (1977) suggested that because the nature of foreign language anxiety was social and academic, it was fundamental to define lines between three performance related anxieties; CA, FNE and TA.

MacIntyre, Noels and Clement (1997) have studied that there is a strong connection between individuals' apprehension regarding their communication and self-perception of communicative competence in second language. While studying test-anxiety, Gordon and Sarason (1980) came up with the idea that foreign language learning in a class involves an on-going evaluation, thus learners fear being exposed to evaluation. Although similar to test anxiety, fear of negative evaluation is broader in scope because it is not limited to testtaking situations; rather, it may occur in any social evaluative situation (Aydin, 2008).

\section{Factors Causing Foreign Language Anxiety}

Khattak, Jamshed, Ahmad and Baig (2011) investigated the causes of English language anxiety in students of Abdul Wali Khan University, Mardan by administering FLCAS (Horwitz et al. 1986) and found out that students felt nervous when the teacher pointed out their mistakes in the class and the ones belonging to poor socio-economic backgrounds felt marginalized. Language anxiety is a psychological idea, which branches out from learner's own 'self', i.e., as an intrinsic motivator (Schwartz, as cited in Scovel, 1991). Hence, foreign language anxiety might be the cause of an inadequate command over the target language, or it may be the result of it. (Sparks and Ganschow as cited in Horwitz, 2001). 
Ortega Cebreros, (2004) proposed that not only the beginners face foreign language anxiety, rather often experienced learners also suffer from high levels of second language anxiety. Foreign language learning anxiety is also known to have disappointingly affected students' grades (Branthmier, 2005). Hashwami (2008) carried out research to study students' attitudes, motivation and anxiety towards learning a foreign language in the multilingual backdrop of Karachi and found out that foreign language classroom anxiety varied from student to student. Whereas, Hussain, Shahid and Zaman (2011) found out that female participants showed lesser anxiety and more positive attitude in class and towards English Language Learning than compared to male students. There are other factors including underprivileged education environment, unsuitable pedagogy and lack of resources which exacerbate language anxiety in Pakistani context (Zubeida, 2012).

English is considered to be the "official language", a prerequisite to success in profession and an "economic guarantor" (Waseem \& Jibeen, 2013), and in their study there was no prominent difference in anxiety scores between male and female belonging to Urdu and English medium schools. Though English is being taught as a subject almost all over Pakistan yet many students are not able to score the required band in IELTS (Hamid, 1991). They repeatedly face failure and experience stress and anxiety, and complain about the loss of money and time, eventually ending up with a compromise with the subject or the university (Raza, 2009).

\section{Methodology}

The type of research was descriptive and quantitative. The inventory used was Foreign Language Classroom Anxiety Scale FLCAS by Horwitz, Horwitz and Cope (1986).

Items on FLCAS sub-scales are divided as follows:

Category 1: CA (items 1, 4, 9, 14, 15, 18, 24, 27, 29, 30, 32)

Category 2: FNE (items 2, 7, 13, 19, 23, 31, 33)

Category 3: TA (items 3, 5, 6, 8, 10, 11, 12, 16, 17, 20, 21, 22, 25, 26, 28)

\section{Reliability}

Horwitz, Horwitz and Cope (1986), founders of FLCAS have proven internal reliability, attaining an alpha coefficient of .93 with all items producing significant corrected itemtotal scale correlations. The researchers conducted a test-retest reliability of the scale stretched over a period of eight weeks produced an $r=.83(p<.001)$.

\section{Population and Sampling}

Three widely commercially acclaimed mainstream English Language Institutes of Lahore were selected for this study. Through convenient sampling 60 students from these institutes were selected who were attending IELTS preparatory classes and enrolled foe IELTS in the month of September 2019. Sample size was 35, 29 and 32 students of classes A, B and C respectively. All the candidates were administered the questionnaire and the turnout was 20,21 and 19 respectively.

\section{Data Analysis and Interpretation}

Using Statistical Package for Social Sciences (SPSS), Independent t-test was applied to find out the relationship between male and female groups' score in FLCAS, ANOVA was applied to check the difference of FLCAS score among candidates having different incomes, age and years of education and Pearson correlation coefficient was applied to find 
out the inter-correlation of FLCAS and IELTS score with age, gender, medium of instruction and years of education of participants respectively.

Data obtained from 60 participants was entered to SPSS to generate the statistical results. All statements on FLCAS are rated on a 5-point Likert Scale where 1 is Strongly Agree and 5 is Strongly Disagree. Total scores of the instrument range from thirty-three to hundred and sixty-five, where lower scores depict high levels of anxiety. 24 items $(1,3,4$, $6,7,9,10,12,13,15,16,17,19,20,21,23,24,25,26,27,29,30,31,33)$ are positive statements, while 9 items $(2,5,8,11,14,18,22,28,32)$ are negative statements.

Table 4.1

Demographic Details of the Participants

\begin{tabular}{|c|c|c|c|}
\hline Variables & Levels & Frequency & Percentage \\
\hline \multicolumn{4}{|l|}{ Age(years) } \\
\hline & $15-25$ years & 34 & 57 \\
\hline & $26-35$ years & 14 & 23 \\
\hline & $36-45$ years & 12 & 20 \\
\hline \multicolumn{4}{|l|}{ Gender } \\
\hline & Male & 25 & 42 \\
\hline & Female & 35 & 58 \\
\hline \multicolumn{4}{|l|}{ Education (years) } \\
\hline & $12-14$ & 27 & 45 \\
\hline & $14-16$ & 11 & 18 \\
\hline & $>16$ & 22 & 37 \\
\hline \multicolumn{4}{|l|}{ Medium of Instruction } \\
\hline & English & 46 & 77 \\
\hline & Urdu & 14 & 23 \\
\hline \multicolumn{4}{|l|}{ Income (Rs.) } \\
\hline & $75,000-100,000$ & 23 & 38 \\
\hline & $100,000-125,000$ & 24 & 40 \\
\hline & $>125,000$ & 13 & 32 \\
\hline \multicolumn{4}{|l|}{ IELTS version } \\
\hline & Academic & 44 & 73 \\
\hline & General Training & 16 & 27 \\
\hline \multicolumn{4}{|l|}{ Previously taken IELTS Test } \\
\hline & Yes & 6 & 10 \\
\hline & No & 54 & 90 \\
\hline \multicolumn{4}{|l|}{$\begin{array}{l}\text { Previously completed any English } \\
\text { Language Course }\end{array}$} \\
\hline & Yes & 8 & 13.3 \\
\hline & No & 52 & 86.7 \\
\hline \multicolumn{4}{|l|}{ Institutes (IELTS Preparatory School) } \\
\hline & English Language A & 21 & 35.0 \\
\hline & English Language B & 20 & 33.3 \\
\hline & English Language C & 19 & 31.7 \\
\hline
\end{tabular}


The given table shows the demographic information of participants. Maximum number of participants belonged to $15-25$ years of age group which was $57 \%$, female participants had a higher frequency, i.e. thirty-five $(58 \%)$, regarding years of education, twenty-seven $(45 \%)$ respondents had $12-14$ years of education and only eleven $(18 \%)$ of the participants had 14-16 years of education and forty-six (77\%) participants had a background of English as a medium of instruction. Most of the participants $(40 \%)$ mentioned their salary/income range as Rs. 75,000-100,000. IELTS Academic Version candidates were forty-four $(73 \%)$ in frequency and only $(10 \%)$ of candidates had attended an English language class before and only eight (13.3\%) participants had already taken IELTS Test previously.

Table 4.2

Spearman's rho Coefficient of Correlation between IELTS Score and Subscales of FLCAS

\begin{tabular}{llllllll}
\hline Variables & Mean & SD & 1 & 2 & 3 & 4 & 5 \\
\hline 1.IELTS score & 2.45 & 0.62 & 1 & & & & \\
2.Communication Apprehension & 4.42 & 0.48 & $.736^{* *}$ & 1 & & & \\
3.Fear of Negative Evaluation & 2.25 & 0.56 & $.733^{* *}$ & $.861^{* *}$ & 1 & & \\
4.Test anxiety & 3.26 & 0.48 & $.759^{* *}$ & $.892^{* *}$ & $.856^{* *}$ & 1 & \\
5.FLCAS score & 2.26 & 0.63 & $.807^{* *}$ & $.877^{* *}$ & $.875^{* *}$ & $.871^{* *}$ & 1 \\
\hline
\end{tabular}

The given table depicts the Spearman's rho coefficient between IELTS score and subscales of FLCAS; 1) CA, 2) FNE and 3) TA. Spearman's rho coefficient between IELTS Score and FLCAS, CA, FNE at TA was $(r=.807),(r=.736),(r=.733)$ and $(r=$ .759) respectively which depicts high levels of anxiety. Similarly there was a strong significant relationship between FLCAS and CA $(r=.877)$, FLCAS and FNE $(r=.875)$ and FLCAS and TA $(r=.871)$.

The following table shows the Pearson correlation coefficient between FLCAS and IELTS Score.

Table 4.3

Pearson correlation coefficient between FLCAS and IELTS Score

\begin{tabular}{ll}
\hline & IELT Score \\
Pearson Correlation & $.860(* *)$ \\
Sig. (2-tailed) & .000 \\
$\mathrm{~N}$ & 60 \\
\hline
\end{tabular}

** Correlation is significant at the 0.01 level (2-tailed).

Value $(\mathrm{p}=.000, \mathrm{p}<.01)$ depicts that there is a strong positive correlation between FLCAS and IELTS Score. The correlation is positive because the values taken for FLCAS Likert scale was 1 for strongly agree and 5 for strongly disagree. Hence high scores of FLCAS means that as the anxiety levels rise, IELTS band decreases.

The following table shows the comparison of different age groups with FLCAS and its subscales. 
Table 4.4

Interrelationship between FLCAS and its Sub-scales, IELTS Score and Age

\begin{tabular}{|c|c|c|c|c|c|c|c|c|}
\hline \multirow{3}{*}{ Variables } & \multicolumn{6}{|c|}{ Age (years) } & \multirow{2}{*}{\multicolumn{2}{|c|}{$\begin{array}{l}\text { One-way } \\
\text { ANOVA }\end{array}$}} \\
\hline & \multicolumn{2}{|c|}{$15-25$} & \multicolumn{2}{|l|}{$26-35$} & \multicolumn{2}{|l|}{$36-45$} & & \\
\hline & Mean & SD & Mean & SD & Mean & SD & $\mathrm{F}$ & $\mathrm{p}$ \\
\hline Communication & 4.30 & 0.39 & 4.69 & 0.64 & 4.46 & 0.39 & 3.83 & 0.028 \\
\hline Apprehension & & & & & & & & \\
\hline Fear of Negative Evaluation & 2.11 & 0.41 & 2.48 & 0.75 & 2.36 & 0.60 & 2.56 & 0.086 \\
\hline Test anxiety & 3.10 & 0.38 & 3.55 & 0.58 & 3.36 & 0.44 & 5.27 & 0.008 \\
\hline FLCAS score & 2.12 & 0.51 & 2.50 & 0.88 & 2.38 & 0.57 & 2.13 & 0.128 \\
\hline
\end{tabular}

In the given table one-way Anova shows that there was a highly significant difference between age groups and CA $(p<.05)$ and Age groups and TA $(p<.05)$. Means depict that age group 15-25 faced higher levels of anxiety $(\mathrm{M}: \mathrm{CA}=4.30, \mathrm{FONE}=2.11, \mathrm{TA}=3.10$, FLCAS=2.12) age group 26-35 and 36-45.

The following table shows the application of Independent t-test to find out the difference between male and female participants on FLCAS and sub-scales.

Table 4.5

Means, SDs of FLCAS Scores of Male and Female Participants

\begin{tabular}{|c|c|c|c|c|c|c|c|}
\hline \multirow[t]{2}{*}{ Variables } & \multicolumn{2}{|l|}{ Male } & \multicolumn{2}{|c|}{ Female } & \multicolumn{3}{|c|}{ Independent samples t test } \\
\hline & Mean & SD & Mean & SD & $\mathrm{t}$ & $\mathrm{df}$ & $\mathrm{P}$ \\
\hline Communication Apprehension & 4.56 & 0.55 & 4.33 & 0.40 & 1.87 & 58 & 0.07 \\
\hline Fear of Negative Evaluation & 2.42 & 0.61 & 2.13 & 0.49 & 2.04 & 58 & 0.05 \\
\hline Test anxiety & 3.38 & 0.52 & 3.17 & 0.43 & 1.77 & 58 & 0.08 \\
\hline FLCAS score & 2.48 & 0.71 & 2.10 & 0.53 & 2.38 & 58 & 0.02 \\
\hline
\end{tabular}

Results depict that there was a significant difference between male and female level of anxiety FLCAS $(\mathrm{p}<.05)$. Mean of FLCAS female participants $(\mathrm{M}: \mathrm{F}=2.10)$ show a higher level of anxiety as compared to mean of FLCAS male participants (M: $M=2.48)$.

The following table shows the Pearson coefficient of correlation between FLCAS and Gender with IELTS Score.

Table 4.6

Pearson correlation coefficient of FLCAS and Genders with IELT Score

\begin{tabular}{ll}
\hline & IELT Score \\
Pearson Correlation & $.860(* *)$ \\
Sig. (2-tailed) & .000 \\
N & 60 \\
Pearson Correlation & -.096 \\
Sig. (2-tailed) & .466 \\
N & 60 \\
\hline
\end{tabular}

** Correlation is significant at the 0.01 level (2-tailed). 
Value $(\mathrm{p}=.466, \mathrm{p}>.05)$ depicts that there is no significant correlation coefficient among FLCAS, Gender and IELTS Score. The findings show that the female participants experience a higher level of anxiety and achieve low IELTS as compared to male participants who experience lower level of anxiety and achieve higher IELTS band.

The following table shows the application of Independent t-test to find out the effect of English and Urdu medium of instruction on FLCAS and sub-scales.

Table 4.7

Means, SDs of FLCAS Scores of English and Urdu Medium Participants

\begin{tabular}{|c|c|c|c|c|c|c|c|}
\hline \multirow{3}{*}{ Variables } & \multicolumn{4}{|c|}{ Medium of instruction } & \multirow{2}{*}{\multicolumn{3}{|c|}{$\begin{array}{l}\text { Independent } \\
\text { samples t test }\end{array}$}} \\
\hline & \multicolumn{2}{|c|}{$\begin{array}{l}\text { English } \\
\text { Medium } \\
\text { (EM) }\end{array}$} & \multicolumn{2}{|c|}{$\begin{array}{l}\text { Urdu } \\
\text { Medium } \\
\text { (UM) }\end{array}$} & & & \\
\hline & Mean & SD & Mean & SD & $\mathrm{t}$ & $\mathrm{df}$ & $\mathrm{p}$ \\
\hline Communication Apprehension & 4.44 & 0.51 & 4.38 & 0.34 & 0.41 & 58 & 0.684 \\
\hline Fear of Negative Evaluation & 2.29 & 0.57 & 2.11 & 0.50 & 1.04 & 58 & 0.303 \\
\hline Test anxiety & 3.27 & 0.50 & 3.22 & 0.41 & 0.33 & 58 & 0.740 \\
\hline FLCAS score & 2.30 & 0.68 & 2.11 & 0.45 & 1.02 & 58 & 0.313 \\
\hline
\end{tabular}

In the given table, findings of independent t-test depict that there was no significant difference between English and Urdu medium of instruction on FLCAS scores ( $p>.05)$. However, means of English and Urdu medium depict that Urdu Medium participants faced a slightly higher level of anxiety as compared to English Medium students.

The following table shows the Pearson coefficient of correlation between FLCAS and Medium of Instruction with IELTS Score.

Table 4.8

Pearson coefficient of correlation of FLCAS and Medium of Instruction with IELTS Score

\begin{tabular}{ll} 
& IELT Score \\
Pearson Correlation & $.860(* *)$ \\
Sig. (2-tailed) & .000 \\
N & 60 \\
Pearson Correlation & $-.275(*)$ \\
Sig. (2-tailed) & .034 \\
N & 60 \\
\hline
\end{tabular}

** Correlation is significant at the 0.01 level (2-tailed).

* Correlation is significant at the 0.05 level (2-tailed).

In the given table value $(p=.034, p<.05)$ depicts that there is a significant correlation between FLCAS and Medium of Instruction with IELTS Score.

The following table shows the comparison of participants' years of education with FLCAS and sub-scales. 
Table 4.9

Interrelationship of different Years of Education Groups with FLCAS and its Subscales

\begin{tabular}{|c|c|c|c|c|c|c|c|c|c|}
\hline \multirow{2}{*}{\multicolumn{2}{|c|}{ Variables }} & \multicolumn{2}{|l|}{$12-14$} & \multicolumn{2}{|l|}{$15-16$} & \multicolumn{2}{|l|}{$>16$} & \multicolumn{2}{|c|}{$\begin{array}{l}\text { One-way } \\
\text { ANOVA }\end{array}$} \\
\hline & & Mean & SD & Mean & SD & Mean & SD & $\mathrm{F}$ & $p$ \\
\hline \multicolumn{10}{|l|}{ Communication } \\
\hline Apprehension & & 4.29 & 0.41 & 4.43 & 0.32 & 4.58 & 0.58 & 2.39 & 0.101 \\
\hline Fear of & Negative & & & & & & & & \\
\hline Evaluation & & 2.10 & 0.42 & 2.25 & 0.38 & 2.43 & 0.72 & 2.18 & 0.122 \\
\hline Test anxiety & & 3.08 & 0.39 & 3.24 & 0.35 & 3.48 & 0.55 & 5.00 & 0.010 \\
\hline FLCAS score & & 2.11 & 0.51 & 2.23 & 0.52 & 2.45 & 0.79 & 1.84 & 0.168 \\
\hline
\end{tabular}

The following table shows the Pearson coefficient of correlation between FLCAS and Years of Education with IELTS Score.

Table 4.10

\section{Pearson coefficient of correlation of FLCAS and Years of Education with IELTS Score}

\begin{tabular}{ll}
\hline & IELT Score \\
Pearson Correlation & $.860(* *)$ \\
Sig. (2-tailed) & .000 \\
N & 60 \\
Pearson Correlation & $.312(*)$ \\
Sig. (2-tailed) & .015 \\
N & 60 \\
\hline
\end{tabular}

** Correlation is significant at the 0.01 level (2-tailed).

* Correlation is significant at the 0.05 level (2-tailed).

In the given table value $(p=.015, p<.05)$ depicts that there is a significant correlation between FLCAS and years of education with IELTS score.

The following table shows the comparison of FLCAS and sub-scales with participants' income.

Table 4.11

Comparison of Income groups with FLCAS and its subscales

\begin{tabular}{|c|c|c|c|c|c|c|c|c|}
\hline \multirow{3}{*}{ Variables } & \multicolumn{6}{|c|}{ Income (Rs.000) } & \multirow{2}{*}{\multicolumn{2}{|c|}{$\begin{array}{l}\text { One way } \\
\text { ANOVA }\end{array}$}} \\
\hline & \multicolumn{2}{|c|}{$75-100$} & \multicolumn{2}{|c|}{$100-125$} & \multicolumn{2}{|l|}{$>125$} & & \\
\hline & Mean & SD & Mean & SD & Mean & SD & $\mathrm{F}$ & $\mathrm{p}$ \\
\hline Communication Apprehension & 4.28 & 0.45 & 4.43 & 0.33 & 4.67 & 0.66 & 3.03 & 0.06 \\
\hline Fear of Negative Evaluation & 2.09 & 0.55 & 2.25 & 0.44 & 2.52 & 0.69 & 2.52 & 0.09 \\
\hline Test anxiety & 3.10 & 0.43 & 3.26 & 0.39 & 3.53 & 0.60 & 3.58 & 0.03 \\
\hline
\end{tabular}


One-way Anova conducted shows that there was a significant relationship among participants' income and FLCAS and its sub-scales $(\mathrm{p}<.05)$. Participants who had Rs.75,000 -100,000 of income felt more anxious (FLCAS M=2.09) as compared to participants who had Rs. 100,000 -125,000 (FLCAS M=2.21) and Rs. 125,000 and above (FLCAS M=2.65).

The following table shows the application of Independent t-test to find out the difference between IELTS Academic and IELTS General Training on FLCAS and sub-scales.

Table 4.12

Means, SDs of FLCAS Scores of Participants taking IELTS Academic and General Training Test

\begin{tabular}{llllllll}
\hline Variables & \multicolumn{2}{c}{ Academic } & General & \multicolumn{2}{l}{$\begin{array}{l}\text { Independent } \\
\text { test }\end{array}$} & samples & $\mathrm{t}$ \\
& & & & & & \\
& Mean & SD & Mean & SD & T & df & p \\
\hline Communication Apprehension & 4.38 & 0.45 & 4.55 & 0.54 & -1.20 & 58 & 0.233 \\
Fear of Negative Evaluation & 2.20 & 0.50 & 2.37 & 0.69 & -0.99 & 58 & 0.325 \\
Test anxiety & 3.19 & 0.45 & 3.43 & 0.53 & -1.75 & 58 & 0.085 \\
FLCAS score & 2.20 & 0.58 & 2.41 & 0.76 & -1.09 & 58 & 0.280 \\
\hline
\end{tabular}

The mean values in given table depicts that reflect that participants of IELTS Academic faced a higher level of anxiety as compared to those who took IELTS General Training (FLCAS M: A= 2.20, $\mathrm{G}=2.41$ ).

The following table shows the application of Independent t-test to find out the difference between FLCAS and sub-scales of the participants who have and have not taken IELTS test previously.

Table 4.13

Means, SDs of FLCAS Scores of Participants who Have and Have Not taken IELTS Test Previously

\begin{tabular}{|c|c|c|c|c|c|c|c|c|}
\hline \multirow[t]{2}{*}{$\begin{array}{l}\text { Previously taken } \\
\text { Test }\end{array}$} & \multirow[t]{2}{*}{ IELTS } & \multicolumn{2}{|l|}{ yes } & \multicolumn{2}{|l|}{ No } & \multicolumn{3}{|c|}{$\begin{array}{l}\text { Independent } \\
\text { samples } t \text { test }\end{array}$} \\
\hline & & Mean & SD & Mean & SD & $\mathrm{t}$ & df & $\mathrm{p}$ \\
\hline $\begin{array}{l}\text { Communication } \\
\text { Apprehension }\end{array}$ & & 4.76 & 0.87 & 4.39 & 0.41 & 1.85 & 58 & 0.070 \\
\hline $\begin{array}{l}\text { Fear of } \\
\text { Evaluation }\end{array}$ & Negative & 2.62 & 0.86 & 2.21 & 0.51 & 1.75 & 58 & 0.085 \\
\hline Test anxiety & & 3.60 & 0.74 & 3.22 & 0.44 & 1.89 & 58 & 0.064 \\
\hline FLCAS score & & 2.75 & 1.04 & 2.20 & 0.56 & 2.05 & 58 & 0.044 \\
\hline
\end{tabular}

Findings in the given table depict that there is a significant difference between FLCAS score of participants who have taken IELTS test previously and those who have not taken IELTS test previously $(\mathrm{p}<.05)$ (FLCAS M: $\mathrm{Y}=2.75, \mathrm{~N}=2.20)$ showing that the participants who have once taken IELTS test felt lesser anxious while taking IELTS test the second time. 
The given table shows the application of Independent t-test to find out the difference between the FLCAS score and sub-scales and the participants who have and have not attended English Language class previously.

Table 4.14

Means, SDs of FLCAS Scores of Participants (previously attended English Language Class)

\begin{tabular}{|c|c|c|c|c|c|c|c|}
\hline \multirow[t]{2}{*}{$\begin{array}{l}\text { Previously completed any English } \\
\text { Language Course }\end{array}$} & \multicolumn{2}{|l|}{ yes } & \multicolumn{2}{|l|}{ No } & \multicolumn{3}{|c|}{$\begin{array}{l}\text { Independent samples } \\
\text { t test }\end{array}$} \\
\hline & Mean & SD & Mean & SD & $\mathrm{t}$ & df & $\mathrm{p}$ \\
\hline Communication Apprehension & 4.23 & 0.31 & 4.45 & 0.49 & -1.25 & 58 & 0.217 \\
\hline Fear of Negative Evaluation & 2.07 & 0.51 & 2.27 & 0.56 & -0.96 & 58 & 0.341 \\
\hline Test anxiety & 3.18 & 0.45 & 3.27 & 0.49 & -0.46 & 58 & 0.646 \\
\hline FLCAS score & 2.19 & 0.53 & 2.27 & 0.65 & -0.34 & 58 & 0.738 \\
\hline
\end{tabular}

The given table shows that there was no significance $(\mathrm{p}>.05)$, whether or not the participants had attended any English language course prior to attending IELTS preparatory classes.

The following table shows the application of One-way Anova to find out the difference between FLCAS and sub-scales of the three IELTS preparatory institutes.

Table 4.15

Comparison of different IELTS Preparatory Institutes' Learners' FLCAS and its subscales

\begin{tabular}{|c|c|c|c|c|c|c|c|c|c|}
\hline \multirow{3}{*}{\multicolumn{2}{|c|}{ Variables }} & \multicolumn{8}{|c|}{ Institutes of English learning } \\
\hline & & \multicolumn{2}{|c|}{ A } & \multicolumn{2}{|c|}{$\mathrm{B}$} & \multicolumn{2}{|l|}{$\mathrm{C}$} & \multicolumn{2}{|c|}{$\begin{array}{l}\text { One-way } \\
\text { ANOVA }\end{array}$} \\
\hline & & Mean & SD & Mean & SD & Mean & $\mathrm{SD}$ & $\mathrm{F}$ & $\mathrm{p}$ \\
\hline $\begin{array}{l}\text { Communicatior } \\
\text { Apprehension }\end{array}$ & & 4.61 & 0.65 & 4.34 & 0.31 & 4.31 & 0.33 & 2.65 & 0.079 \\
\hline $\begin{array}{l}\text { Fear of } \\
\text { Evaluation }\end{array}$ & Negative & 2.48 & 0.75 & 2.16 & 0.46 & 2.09 & 0.27 & 2.97 & 0.059 \\
\hline Test anxiety & & 3.47 & 0.63 & 3.18 & 0.36 & 3.10 & 0.29 & 3.65 & 0.032 \\
\hline FLCAS score & & 2.55 & 0.85 & 2.18 & 0.49 & 2.03 & 0.31 & 3.99 & 0.024 \\
\hline
\end{tabular}

Results in the given table show that there was significant difference between language anxieties experienced by students of three different IELTS Preparatory Institutes $(\mathrm{p}<.05)$, FLCAS score means $(\mathrm{M}: \mathrm{A}=2.55, \mathrm{~B}=2.18, \mathrm{C}=2.03)$.

\section{Discussion}

Findings depict that younger students faced a higher level of foreign language anxiety, students of age group 15-25 years experienced highest level of test anxiety, and female students had a higher rate of foreign language anxiety and they achieved lesser scores as compared to male participants who experienced lesser degree of foreign language anxiety and achieved higher band score in IELTS Speaking Module. This result opposes Hussian, Shahid and Zaman's (2011) study where female students showed lesser anxiety and more positive attitude in class towards English Language as compared to male participants. 
Similar to Mansoor's (2004) study proposing that English Language was a hurdle for students who had been taught through a weaker medium of English Language Learning (or Urdu medium) results of this study depicted that students who were taught in Urdu medium school/institutes during their academic lives, experienced higher level of anxiety as compared to those students whose medium of instruction was English.

This study indicated that students had a strong negative correlation between foreign language anxiety and years of education. This depicts stark contradiction with the research (Onwvegbuzie, Bailey \& Daley, 1999) where freshmen and sophomores reported lowest levels of foreign language anxiety and as the years of education increased, language anxiety increased as well.

Three sub-scales of FLCAS: CA, FNE and TA provided significant findings with respect to the current study. Firstly Spearman's rho coefficient between IELTS speaking score and Communication Apprehension was $(\mathrm{r}=.736)$ depicting high level of anxiety. The level of trepidation and nervousness has the possibility to intensify individuals' language proficiency if they think their language competence is low (MacIntyre, Noels \& Clement, 1997). Results of the current study showed that students' CA had adverse effects on students' performance which means that students who experienced higher level of CA scored lower band in IELTS speaking module. Secondly, Spearman's coefficient of correlation between IELTS speaking score and FNE $(\mathrm{r}=.733)$ described high level of anxiety experienced while speaking a foreign language arousing fear of being judged for the spoken language. Awan, Azhar, Anwar and Naz (2010) while studying impact of language anxiety on participants' performance found out that people were highly anxious to use a foreign language in front of others. Thirdly Spearman's rho coefficient between IELTS Score and test anxiety $(r=.759)$ depicts strong negative correlation of test anxiety with FLCAS. These results are broadly consistent with Khattak, Jamshed and Baig's (2011) research where they surveyed 62 students and interviewed 10 students who volunteered and responded that they felt anxious of making errors and the teacher correcting them, they also felt nervous regarding failing the exam.

An interesting finding during this study depicted that high achievers who had scored 7 or 7.5 band had also experienced some degree of foreign language anxiety. This finding correlates with Ortega Cebreros, (2004) that not only the students at beginners' level but those at the advanced and experienced learners also experience language anxiety.

Pakistan is already a rich zone of multicultural languages, which is the prime reason why English Language is a second, third or even fourth language for our people (Sarwar, 2002). In this scenario, it is crucial to communicate with the foreign world using proficient English Language and synchronize with them in a language being spoken worldwide. As far as IELTS is concerned it might seem a small part of English language learning, yet it is a fundamental one (Memon, 2005). Candidates pay a handsome amount of money for the test and if they fail to achieve their required band, they end up wasting a lot of money. Keeping in view these factors, examining the impact of language anxiety upon IELTS Scores among students preparing for IELTS is just a fraction of a larger issue, i.e. language proficiency and language anxiety. Keeping aside students' current proficiency, English Language Institutes may work on the duration of the courses and test preparation because IELTS preparation involves both language learning and language testing, thus involving language anxiety and test anxiety (Memon, 2005). 


\section{Research Limitations and Directions for Future Studies}

This research holds certain limitations ascribable to time, availability of resources and authorization. Firstly, sample size was reduced to 60 due to low turnout and mal responses. Moreover, not all candidates enrolled in class of July-August took the test in September 2019. Secondly, overall ratio of female students was more than male students, which affected the results. It is anticipated that equal number of ratios of incorporated demographics would produce more generalizable results.

While studying FLA, factors affecting foreign language anxiety, are deeply related to an individual's frame of reference. Foreign language anxiety cannot be studied or measured in isolation. All the related elements are of prime importance and should be studied how they influence an individual's foreign language performance and achievement. This research can be carried forward while making certain changes to it. Some of the recommendations are as follows;

Sample size studied should be large enough to be generalised. Samples should be categorized according to their IELTS Version; General Training or Academic, their on campus and actual scores should be studied to identify the difference of their performance for different testing bodies. Survey should be conducted right after the speaking class to achieve the best possible genuine responses. Moreover FLA varies from student to student, for which students' attitude, motivation and perception should be studied as an intervening variable towards learning a foreign language.

\section{Conclusion}

Findings depict that the participants experience a high level of FLA; they faced CA, FNE and TA. This experienced anxiety in result influence their IELTS speaking scores and affect their performance. Female participants and younger participants belonging to 15-25 years of age faced high level of language anxiety. Similarly students who had 12-14 years of education and those who had Urdu as a medium of instruction in their academic history experienced high level of language anxiety. Moreover, students with lesser income faced higher levels of FLA and students who had previously taken IELTS faced lesser FLA than the ones who had not.

\section{References}

Aida, Y. (1994). Examination of Horwitz, Horwitz, and Cope's construct of foreign language anxiety: The case of students of Japanese. The modern language journal, 78(2), 155-168.

Association, A. A. (2004). Code of ethics of the American Anthropological Association: American Anthropological Association.

Azher, M., Anwar, M. N., \& Naz, A. (2010). An investigation of foreign language classroom anxiety and its relationship with students' achievement. Journal of College Teaching and Learning, 7(11), 33.

Bailey, K. M. (1983). Competitiveness and anxiety in adult second language learning: Looking at and through the diary studies. Classroom oriented research in second language acquisition, 67-102.

Bandura, A. (1989). Six theories of child development. Annals of child development, 6, 1-60.

Brantmeier, C. (2005). Anxiety about L2 reading or L2 reading tasks? A study with advanced language learners. Reading, 5(2).

Brown, H. D., \& 吳一安. (2000). Principles of language learning and teaching.

Budin, M. (2014). Investigating the relationship between English language anxiety and the achievement of school based oral English test among Malaysian Form Four students. 
International Journal of Learning, Teaching and educational research, 2(1).

Campbell, C. M., \& Ortiz, J. (1991). Helping students overcome foreign language anxiety: A foreign language anxiety workshop. Language anxiety: From theory and research to classroom implications, 153-168.

Cassady, J. C. (2010). Anxiety in schools: The causes, consequences, and solutions for academic anxieties (Vol. 2): Peter Lang.

Cebreros, A. M. O. (2003). Measuring language anxiety perceived by Spanish university students of English. Bells: Barcelona English language and literature studies, 12.

Clément, R., Gardner, R. C., \& Smythe, P. C. (1977). Motivational variables in second language acquisition: A study of Francophones learning English. Canadian Journal of Behavioural Science/Revue canadienne des sciences du comportement, 9(2), 123.

Desrochers, A., \& Gardner, R. C. (1981). Second-Language Acquisition: An Investigation of a Bicultural Excursion Experience.

Dewaele, J.-M. (2007). The effect of multilingualism, sociobiographical, and situational factors on communicative anxiety and foreign language anxiety of mature language learners. International Journal of Bilingualism, 11(4), 391-409.

Dudovskiy, J. (2016). The Ultimate Guide to Writing a Dissertation in Business Studies: A step bystep assistance. Research-methodology. net.

Ellis, R. (1994). The study of second language acquisition: Oxford University.

Ethridge, D. E. (2004). Research methodology in applied economics: organizing, planning, and conducting economic research: Blackwell publishing Ames.

Fishman, J. A., \& García, O. (2011). Handbook of language and ethnic identity: The successfailure continuum in language and ethnic identity. Vol. 2: Oxford: Oxford University Press.

Fox, W., \& Bayat, M. S. (2008). A guide to managing research: Juta and Company Ltd.

Gordon, E. M., \& Sarason, S. B. (1955). The relationship between "test anxiety" and "other anxieties". Journal of personality, 23(3), 317-323.

Hashwani, M. S. (2008). Students' attitudes, motivation and anxiety towards English language learning. Journal of Research and Reflections in Education, 2(2).

Hilgard, E. R., Atkinson, R. C., \& Atkinson, R. L. (1975). Introduction to psychology: Oxford and IBH Publishing.

Horwitz, E. (1984). What ESL students believe about language learning. Paper presented at the unpubl. paper presented at the TESOL Annual Meeting, Houston.

Horwitz, E. (2001). Language anxiety and achievement. Annual review of applied linguistics, 21, 112-126.

Hussain, M. A., Shahid, S., \& Zaman, A. (2011). Anxiety and attitude of secondary school students towards foreign language learning. Procedia-Social and Behavioral Sciences, 29, 583-590.

James, C. (2013). Errors in language learning and use: Exploring error analysis: Routledge.

Jun Zhang, L. (2001). Exploring variability in language anxiety: Two groups of PRC students learning ESL in Singapore. RELC Journal, 32(1), 73-91.

Khattak, Z. I., Jamshed, T., Ahmad, A., \& Baig, M. N. (2011). An investigation into the causes of English language learning anxiety in students at AWKUM. Procedia-Social and Behavioral Sciences, 15, 1600-1604.

Kleinmann, H. H. (1977). Avoidance behavior in adult second language acquisition. Language learning, 27(1), 93-107.

Koch, A. S., \& Terrell, T. D. (1991). Affective reactions of foreign language students to natural approach activities and teaching techniques. Language anxiety: From theory and research to classroom implications, 109-126.

Liu, M., \& Huang, W. (2011). An exploration of foreign language anxiety and English learning motivation. Education Research International, 2011.

MacIntyre, P. D. (1999). Language anxiety: A review of the research for language teachers. Affect in foreign language and second language learning: A practical guide to creating a lowanxiety classroom atmosphere, $24,41$. 
MacIntyre, P. D., \& Gardner, R. C. (1991). Language anxiety: Its relationship to other anxieties and to processing in native and second languages. Language learning, 41(4), 513-534.

MacIntyre, P. D., \& Gardner, R. C. (1994). The subtle effects of language anxiety on cognitive processing in the second language. Language learning, 44(2), 283-305.

MacIntyre, P. D., Noels, K. A., \& Clément, R. (1997). Biases in self-ratings of second language proficiency: The role of language anxiety. Language learning, 47(2), 265-287.

Malik, F. J. (1996). The teaching of English in Pakistan: A study in teacher education: Vanguard.

Mallow, J. V. (1981). Science anxiety: Fear of science and how to overcome it: Thomond Press.

Mansoor, S., Meraj, S., \& Tahir, A. (2004). Language Policy, Planning, \& Practice: A South Asian Perspective: Oxford University Press.

McCroskey, J. C. (1977). Oral communication apprehension: A summary of recent theory and research. Human communication research, 4(1), 78-96.

McCroskey, J. C. (1982). Oral communication apprehension: A reconceptualization. Annals of the International Communication Association, 6(1), 136-170.

Mustafa, Z. (2012). Pakistan ruined by language myth. The Guardian, 10.

Noreen, S., Ahmed, M., \& Esmail, A. (2015). Role of Students' Motivation, Attitude and Anxiety in Learning English at Intermediate Level in Pakistan: A Gender Based Study. Educational Research International, 4(2), 96-108.

Onwuegbuzie, A. J., Bailey, P., \& Daley, C. E. (1999). Factors associated with foreign language anxiety. Applied Psycholinguistics, 20(2), 217-239.

Phillips, E. M. (1992). The effects of language anxiety on students' oral test performance and attitudes. The modern language journal, 76(1), 14-26.

Price, M. L. (1991). The subjective experience of foreign language anxiety: Interviews with highly anxious students. Language anxiety: From theory and research to classroom implications, 101-108.

Rahman, T. (1997). The medium of instruction controversy in Pakistan. Journal of Multilingual and Multicultural Development, 18(2), 145-154.

Rahman, T. (2001). English-teaching institutions in Pakistan. Journal of Multilingual and Multicultural Development, 22(3), 242-261.

Sarason, I. G. (1980). Test anxiety: Theory, research, and applications: Lawrence Erlbaum Assoc Inc.

Scovel, T. (1978). The effect of affect on foreign language learning: A review of the anxiety research. Language learning, 28(1), 129-142.

Shami, P. A., \& Hussain, K. S. (2006). Development of education in Pakistan: Academy of Educational Planning and Management, Ministry of Education.

Shams, A. N. (2006). Use of Computerized Pronunciation Practice in the Reduction of Foreign Language Classroom Anxiety.

Singhal, V., \& Neas, L. (2011). Defining second language acquisition. Bright Hub Inc.

Sparks, R., \& Ganschow, L. (1993). Searching for the cognitive locus of foreign language learning difficulties: Linking first and second language learning. The modern language journal, 77(3), 289-302.

Spielberger, C. D. (1983). Manual for the State-Trait Anxiety Inventory STAI (form Y)(" selfevaluation questionnaire").

Spielberger, C. D. (2010). State-Trait anxiety inventory: Wiley Online Library.

Statistics, L. (2013). Independent t-test for two samples.

Sultan, S. (2012). Students' perceived competence affecting level of anxiety in learning English as a foreign language. Pakistan Journal of Psychological Research, 27(2), 225.

To, S. H. Data Mining: Simple Definition, Uses \& Techniques.

Tobias, S. (1978). Overcoming mathematics anxiety: New York: Norton.

Waseem, F., \& Jibeen, T. (2013). Anxiety amongst learners of English as a second language: An examination of motivational patterns in the Pakistani context. International Journal of Humanities and Social Science, 3(16), 174-184. 
Young, D. J. (1991). Creating a Low-Anxiety Classroom Environment: What Does Language Anxiety Research Suggest? The modern language journal, 75(4), 426-437.

Young, D. J. (1992). Language anxiety from the foreign language specialist's perspective: Interviews with Krashen, Omaggio Hadley, Terrell, and Rardin. Foreign Language Annals, 25(2), 157-172.

Zafar, S., \& Meenakshi, K. (2012). Individual Learner Differences and Second Language Acquisition: A Review. Journal of Language Teaching \& Research, 3(4).

Zhang, W., \& Liu, M. (2013). Evaluating the impact of oral test anxiety and speaking strategy use on oral English performance. The Journal of AsiaTEFL, 10(2), 115-148. 